\title{
ENSINO DA HABILITAÇÃO EM ENFERMAGEM MEDICO-CIRÚRGICA DA ESCOLA DE ENFERMAGEM DA USP Aspectos da disciplina Enfermagem Médico-Cirúrgica II
}

\author{
Maria Sumie Koizumi* \\ Célia Pires de Araújo* \\ Mcema Guedes Barbato* \\ Yoriko Kamiyama* \\ Coracy Graça Martins* \\ Miako Miura* \\ Edna Ikumi Umebayashi*
}

KOIZUMI, M. S.; ARAƯJO, C. P.; BARBATO, M. G.; KAMIYAMA, Y.; MARTINS, C. G.; MIURA, M.; UMEBAYASHI, E. I. - Ensino da habilitação em enfermagem médico-cirúrgica - aspectos da disciplina enfermagem médico-cirúrgica II. Rev. Esc. Enf. USP, 10 (3):331-339, 1976.

As autoras apresentam os aspectos gerais do planejamento da disciplina Enfermagem Médico-Cirúrgica II, do curso de Habilitação em Enfermagem Médico-Cirúrgica, desde que este foi iniciado em 1973 na Escola de Enfermagem da USP. Discorrem sobre a programação atual $e$ anexam no final o esquema do plano de ensino da disciplina.

\section{INTRODUÇÃO}

O Conselho Federal de Educação, após estudos minuciosos sobre o projeto "Currículo Mínimo dos Cursos de Graduação em Enfermagem", apresentados por um grupo de especialistas da área à Comissão de Revisão dos Currículos, aprovou os mesmos sob o Parecer n. ${ }^{\circ} 163$ de 28/01/72.

* Docentes da disciplina Enfermagem Médico-Cirúrgica II, do Departamento de Enfermagem Médico-Cirúrgica da Escola de Enfermagem da USP. 
Esse currículo mínimo visualiza a complexa formação do enfermeiro e como cita a própria introdução do Parecer, trata-se "daquele profissional a quem ficaram comedidas as tarefas mais complexas transcedentes e de maior responsabilidade da enfermagem, inclusive a pesquisa a docência em nivel superior, mediante estudos complementares de pósgraduação".

Como vimos nesse parecer, o artigo $1^{\circ}$ estabelece as fases sucessivas do Currículo, ou seja:

- pré-profissional;

- tronco profissional;

- habilitação.

Nesta nossa comunicação trataremos de focalizar, entre as habilitações recomendadas, a mais recente delas, surgida com a reestruturação do Currículo Mínimo de Enfermagem - Enfermagem Médico Cirúrgica.

Essa habilitação inclui como disciplinas Administração de Centro Cirúrgico, Enfermagem em Pronto Socorro, Unidades de Recuperação e de Cuidados Intensivos e Administração de Serviços de Enfermagem Hospitalar. A Escola de Enfermagem da Universidade de São Paulo, consciente da necessidade dessa habilitação, procurou de imediato traçar um plano para a implementação da mesma. Neste trabalho serão enfocados apenas as incluídas na disciplina Enfermagem Médico Cirúrgica II, desenvolvida no primeiro semestre do ano acadêmico. A Administração de Centro Cirúrgico e de Serviços de Enfermagem Hospitalar estão entregues às docentes daquelas áreas. Vejamos como se processou esse planejamento.

Caracteristicas do planejamento - aspectos gerais: Seleção do corpo docente

Foram escolhidas professoras das seguintes áreas: Enfermagem Médica e Enfermagem Cirúrgica e, mais recentemente, docentes de Enfermagem em Doenças Transmissíveis.

Estabelecimento dos comportamentos iniciais, do objetivo a 
ser alcançado, estratégias, avaliação e carga horária a ser exigida

Foram feitos estudos sobre os pré-requisitos, em seguida traçados os objetivos comportamentais e finalmente estabelecido o conteúdo programático. Os tipos de estratégias e de avaliação do rendimento escolar foram selecionados e introduzidos no decorrer de toda a programação. Esses elementos serão abordados na apresentação do plano de ensino.

Seleção dos campos de estágio

Consistiu em identificar as unidades de terapia intensiva e de recuperação que serviriam como campo de estágio e cuja planta física e funcionamento preenchesse os requisitos mínimos para atingirmos os objetivos traçados no programa, isto é, que os alunos pudessem aplicar os conhecimentos adquiridos em aulas teórico-práticas e desenvolver habilidades e atitudes específicas dessas áreas. Após visitas de observação, foram selecionadas as seguintes áreas: Unidades Coronariana, Respiratória, Pós-Anestésica, de Hemodiálise e Diálise Peritonial, de Recuperação Cirúrgica, de Neurocirurgia, de Queimados, de Tetânicos e Unidades de Emergência. Essas Unidades pertencem ao Hospital das Clínicas da Faculdade de Medicina da Universidade de São Paulo, ao Instituto de Cardiologia "Dante Pavanezzi" da Secretaria de Saúde do Estado de São Paulo e à Sociedade Beneficente de Senhoras - Hospital Sírio-Libanês.

Passaremos a descrever como se desenvolve atualmente o plano de ensino, após três anos de experiência didática, acompanhada de avaliação.

\section{DESENVOLVIMENTO DO ENSINO}

O conteúdo programático é iniciado com um bloco teórico cuja duração é de quatro semanas. A seguir, é desenvolvido o ensino teórico-prático no campo, com duração de doze semanas.

Para tornar a exposição mais objetiva passaremos a descrever primeiro o desenvolvimento do bloco teórico e depois o trabalho de campo. 


\section{a) Bloco Teórico}

O bloco teórico tem por finalidade conduzir o aprendizado do estudante ao nível em que este possa de imediato desempenhar simultaneamente suas funções em unidades de terapia intensiva (UTI), unidades de recuperação (UR) e pronto socorros (PS). Para tanto já devem ter uma base científica, que é necessária para uma atuação adequada.

A seqüência de desenvolvimento do referido bloco teórico, apresentada em unidades, visa a alcançar uma melhor finalidade didática, começando-se pelo básico e atingindo, depois, as especializações (anexo n. 1$)$.

$\mathrm{Na}$ metodologia empregada constam: preleções, discussões em grupo; demonstrações, visitas e observações com apresentação de relatórios.

Uma parte da avaliação é feita por meio de provas de aproveitamento, que podem ser testes objetivos ou dissertações. Salientamos, no entanto, que a avaliação é feita continuamente durante o decorrer do ensino no campo.

\section{b) Trabalho de Campo}

Imediatamente após o bloco teórico, inicia-se o desenvolvimento do trabalho de campo. Consta de duas atividades básicas: o estágio (trabalho de campo), com ensino individualizado e supervisão contínua, e, trabalhos escritos e orais, abordando temas referentes a UTI, UR e PS.

Os estágios são efetuados em diversas UTI, UR e PS dos hospitais governamentais e particulares mencionados anteriormente.

Os estudantes são sub-divididos em grupos de 2 a 4 elementos, que estagiam por um período de 2 a 4 semanas nas unidades selecionadas, obedecendo a um sistema de rodízio pré-determinado.

A jornada semanal para essa atividade está fixada em 30 horas. A assistência de enfermagem é prestada, com aplicação do processo de enfermagem, adaptado a pacientes agudos graves. 
Os trabalhos escritos desenvolvidos em paralelo têm por finalidade ampliar a experiência do estudante em relação a UTI, UR e PS.

Para esta atividade, no início do bloco teórico é apresentada uma lista de temas gerais referentes à assistência de enfermagem ao paciente de UTI. Os estudantes são subdivididos em grupos de 2 a 3 elementos, diferentes daqueles que compõem o grupo de estágio, e estes selecionam um tema dentre os listados, a fim de desenvolvê-lo no período de 10 semanas, paralelamente ao estágio. Para cada tema é determinado um docente orientador que acompanha todo o desenvolvimento do trabalho.

Dos temas apresentados, alguns estudantes optam pela utilização da metodologia científica para elaborar trabalho de pesquisa, e para tal são orientados. Outros preferem fazer uma análise de situação e revisão bibliográfica. Na segunda opção os estudantes visitam algumas UTI e UR existentes na cidade de São Paulo, fazem o inquérito relacionado com o tema a ser desenvolvido e fundamentam com bibliografia atualizada, nacional e estrangeira.

Nas duas últimas semanas do ensino da disciplina, os trabalhos elaborados são apresentados por escrito e também oralmente, para toda a classe. A avaliação é efetuada mediante roteiro elaborado para essa finalidade.

\section{CONCLUSÃO E SUGESTŐES}

Esse planejamento foi o estabelecido para a quarta turma que fez opção pela Habilitação em Enfermagem Médico-Cirúrgica, nesta Escola. A experiência, porém, começou em 1973 e, a partir daquele ano, baseadas nas avaliações contínuas dos estudantes, dos enfermeiros do campo e das docentes, introduzido algumas modificações no planejamento, as quais já constam do programa apresentado nesta comunicação. Foram gradativamente acrescidos novos temas ao bloco teórico, nele introduzidos novos trabalhos de campo e novos instrumentos para avaliação.

Resta-nos acrescentar que os estudantes atuando em campo devem e sempre foram supervisionados pelas docentes da Escola e estas 
receberam inestimável colaboração, tanto teórica como prática, das enfermeiras e dos médicos das unidades correspondentes.

E ainda pequena a nossa experiência com este tipo de habilitação para fazer uma avaliação precisa; entretanto, acreditamos que muitos dos objetivos traçados foram alcançados.

Temos acompanhado de maneira informal os enfermeiros que fizeram essa habilitação e parece-nos que a sua adaptação às unidades de terapia intensiva é satisfatória e eficiente. Aconselhamos que esse acompanhamento seja sistematizado pelas docentes da Escola de Enfermagem e que possamos no futuro determinar um currículo cujos objetivos traçados sejam realmente pertinentes às necessidades do estudante, para que esse possa assistir o paciente, geralmente portador de uma patologia grave, de maneira adequada, isto é, aplicando os conhecimentos teóricos, agindo com habilidade precisa e antes de tudo não esquecendo que esse indivíduo é um ser humano, com as suas necessidades bio-psico-sócio e espirituais gravemente afetadas.

KOIZUMI, M. S.; ARAÛJO, C. P.; BARBATO, M. G.; KAMIYAMA, Y.; MARTINS, C. G.; MIURA, M.; UMEBAYASHI, E. I. - Teaching medical-surgical nursing in especialization course - University of São Paulo's Nursing School - General aspects of medicalsurgical nursing II discipline. Rev. Esc. Enf. USP, 10(3):331-339, 1976.

The authors present general aspects about planning a program in Medical-Surgical Nursing II in Especialization Course, since it's start in 1973 at University of São Paulo's Nursing School. It is presented the actual program including an esquematic plan regarding the teaching of the subject. 


\section{ANEXO N. $: 1$}

Plano de ensino de ENFERMAGEM MÉDICO-CIRÚRGICA II

\section{Carga Horária}

Créditos-aula $=(8)=120$ horas

Créditos-trabalhos $=(14)=420$ horas

Total $=(22)=540$ horas

\section{OBJETIVOS}

Terminada a disciplina e tendo atuado em unidades de terapia intensiva, unidade de recuperação e pronto socorro, o aluno deverá ser capaz de:

1. discorrer sobre a etiologia, fisiopatologia, tratamento e complicações das coronariopatias, insuficiência renal aguda, estados de choque, insuficiência respiratória aguda, politraumatizados e afeç̧ões cirúrgicas do coração, vasos da base e neurocirúrgicas.

2. fazer, interpretar e registrar exames complementares específicos.

3. executar o processo de enfermagem em pacientes agudos graves.

4. manejar e controlar aparelhos usados nas referidas unidades: monitores, desfibriladores, marca-passos, respiradores, aspiradores e hemodializadores.

PROGRAMA

Unidade I - Planejamento, organização, implantação e funcionamento das unidades de terapia intensiva, unidades de recuperação e pronto socorros. 
Unidade II - Assistência de enfermagem a pacientes com desequilíbrio hidreletrolítico e ácido-básicos.

Unidade III - Assistência de enfermagem a pacientes com insuficiência respiratória aguda.

Unidade IV - Assistência de enfermagem a pacientes com insuficiência renal aguda.

Unidade $\quad \mathrm{V}$ - Assistência de enfermagem a pacientes em estado de choque.

Unidade VI - Assistência de enfermagem a pacientes com coronariopatias e disritmias graves.

Unidade VII - Assistência de enfermagem a pacientes submetidos a cirurgia cardíaca.

- Unidade VIII - Assistência de enfermagem a politraumatizados.

Unidade IX - Assistência de enfermagem a pacientes neurocirúrgicos.

\section{ESTRATEGIAS DE ENSINO}

Preleções;

Discussões em grupo;

Estudo dirigido;

Demonstrações;

Seminários;

Trabalho de campo com ensino e supervisão;

Visitas a serviços especializados.

\section{AVALIAÇÃo}

Provas de aproveitamento;

Boletim de avaliação referente à atuação do aluno no trabalho de campo;

Participação do aluno em seminários;

Trabalhos escritos. 


\section{BIBLIOGRAFIA BÁSICA}

1. BRUNNER, L. S. et al. - Enfermería medico-quirurgica. 2. ed. México, Interamericana, 1971.

2. CARINI, E. \& OWENS, G. - Neurological and neurosurgical nursing. Saint Louis, Mosby, 1970.

3. BUDIN, D. - Interpretação rápida do ECG. Rio de Janeiro, Publicações científicas Ltda., 1974.

4. MELTZER, L. E. et al. - Cuidados intensivos para el paciente coronario. México, La Prensa Médica Mexicana, 1973.

5. SABBAGA, E. \& VASCONCELOS, E. - Insuficiência renal aguda. São Paulo, Sarvier, 1970.

6. SECOR, J. M. A. - Patient care in respiratory problems. Phyladelphia, Saunders, 1969.

7. SMITH, D. \& GIPS, C. - Enfermería medico-quirúrgica. 3. ed. México, Interamericana, 1973.

8. STORLIE, F. et al. - Principles of intensive nursing care. New York, Meredith Corporation, 1972.

9. SYKES, M. K. - Insuficiencia respiratoria. Barcelona, Toray, 1970.

10. THAL, A. P. - Shock: base fisiologica para sua tratamiento. Buenos Aires, Intermedica, 1973.

11. ZERBINI, E. J. - Clínica cirúrgica Alípio Correa Neto. 3. ed. São Paulo, Sarvier, 1974. v. 3. 